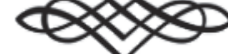

About Truth, Lie and Post-Truth.

Elements for a Philosophy of Information

\title{
Sobre verdad, mentira y posverdad. Elementos para una filosofía de la información
}

\author{
Enrique Herreras \\ Universitat de València \\ enrique.herreras@uv.es \\ Marina García-Granero \\ Universitat de València \\ marina.garcia-granero@uv.es
}

DOI: https://doi.org/10.15366/bp.2020.24.008

Bajo Palabra. II Época. № 24. Pgs: 157-176 
Recibido: 01/03/2020

Aprobado: 28/07/2020

\section{Resumen}

El problema de la "verdad" es uno de los más presentes en la comunicación desde los orígenes de la prensa y uno de los nucleares de la filosofía desde sus comienzos. En la actualidad, este asunto sigue latente en los medios de comunicación, incluso tras los cambios acaecidos con los nuevos dilemas abiertos por los cambios tecnológico-productivos. Estos dilemas están a menudo relacionados con la importancia que ha adquirido la opinión pública en nuestras democracias insertas en un mundo globalizado. Dado el peso de la opinión publicada, vemos necesario revisar, desde un planteamiento de lo que denominamos filosofía de la información periodística, los conceptos de verdad y mentira en sentido periodístico. En primer lugar, analizamos dos modos de entender dicha información: el periodismo objetivista y el periodismo posmoderno. Este es un paso previo para adentrarnos en una posible solución a esa dicotomía a partir de una reconsideración del perspectivismo, en concreto las aportaciones de F. Nietzsche y J. Ortega y Gasset. El objetivo finalmente es que sus aportaciones nos sirvan para reconstruir un cimiento sólido y superar la posverdad.

Palabras clave: verdad, objetivismo, posmodernidad, posverdad, perspectivismo.

\section{Abstract}

"Truth" has been one of the central subjects in communication since the origins of the press and one of the core subjects of philosophy from its very beginnings. The matter is still latent in the mass media today, even after the changes brought about by new dilemmas resulting from developments in technology and production. These dilemmas are often related to the importance of public opinion in our democracies as part of the globalised world. In view of the significance of the published opinion, we see the need to review, from the philosophy of information approach, the concepts of journalistic truth and lie. Firstly, we analyse such information from two perspectives, those of positivist journalism and post-modern journalism, as a preliminary step before exploring a possible solution to that dichotomy by reconsidering perspectivism, and the contributions of F. Nietzsche and J. Ortega y Gasset in particular. Ultimately, we hope their philosophical contributions will serve to rebuild a solid foundation and to overcome the post-truth era.

Keywords: truth, positivism, postmodernism, post-truth, perspectivism. 
$\mathrm{E}$ presente trabajo tiene como objetivo dar respuestas, desde una filosofía de la información periodística, al debate abierto por el fenómeno denominado "posverdad". Un término que, según M. Ferraris ${ }^{1}$, expresa las características esenciales de la opinión pública contemporánea. Si bien no coincidimos con esta sintomatología, demasiado generalista, sí es evidente que, de un tiempo a esta parte, se está produciendo un aumento de prácticas en este sentido, sobre todo en las redes, un espacio que no tiene todavía leyes propias. Y es también axiomático que este concepto conlleva un claro ataque a la línea de flotación del periodismo que no es otra cosa que "decir la verdad" 2 .

La posverdad está creando una preocupación que no puede quedarse en el horizonte profesional, porque la respuesta a este fenómeno tiene evidentes repercusiones políticas y sociales. Si la verdad es una cualidad sine qua non del derecho a la información, la posverdad va más allá de la libertad de expresión porque dificulta distinguir entre realidad y ficción. Esta percepción nos enlaza con la opinión pública, un término básico en la actual reflexión sobre la democracia. La presencia de los medios de comunicación adquiere una relevancia especial si pensamos que, dentro de las condiciones que ofrecen legitimidad a la profesión del periodista, se encuentra también la responsabilidad para poder infundir confianza, porque sin esta confianza en la información recibida, la ciudadanía se encuentra desasistida, hasta el punto de que se podría hablarse de una "construcción mediática de la realidad" ${ }^{3}$. A este respecto, A. Honneth, en su esbozo de "eticidad democrática", subraya que "la habilidad de los medios de producción de ideas, para componer descripciones virtuales de la realidad, es uno de los grandes desafíos de la vida pública democrática" ${ }^{4}$. Y más allá, la posverdad parece una auténtica amenaza a la democracia 5 .

Comprender el fenómeno de la posverdad supone, por tanto, indagar los motivos por los que se ha perdido en gran medida la fe en la "verdad" en los medios. Si

Esta publicación ha recibido el apoyo del proyecto de Investigación Científica y Desarrollo PID2019109078RB-C22 financiado por el Ministerio de Ciencia e Innovación. Marina García-Granero agradece el soporte de una ayuda a contratos FPU (FPU15/04085).

1 Ferraris, Maurizio, Postverità e altri enigmi, Bologna, Il Mulino, 2017.

2 Kovach, Bill y Rosenstiel, Tom, Los elementos del periodismo, Madrid, Santillana, 2012.

3 Cortina, Adela, "Periodismo imprescindible", El País, 29.01.2018. Disponible en: https://elpais.com/elpais/2018/01/26/opinion/1516968330_170402.html

4 Honneth, Axel, El derecho de la libertad. Esbozo de una eticidad democrática. Madrid, Katz, 2014, p. 395.

5 D'Ancona, Matthew, Post Truth. The New War on Truth and How to Fight Back, London, Ebury Press, 2017. Traducción española: Posverdad, Madrid, Alianza. 
bien es preciso que el periodismo se enfrente, como cualquier otra actividad humana, a su propia realidad práctica y límites, lo es también que la filosofía puede aportar alguna solución. La verdad del periodismo no tiene un mismo significado que el de la filosofía, pero existen vasos comunicantes, aunque solo fuese por el motivo de que los medios utilizan frecuentemente categorías filosóficas y no renuncian a conceptos epistemológicos como "realidad", "hechos", "verdad" y "objetividad".

Esto nos conduce a la siguiente pregunta de N. Catelli: "si hay una posverdad, ¿qué hubo antes?” ${ }^{\circ}$. Una primera respuesta proviene de la tradición filosófica aristotélica que considera la verdad como "correspondencia" o "adecuación" entre discurso y mundo real. Es, por tanto, una capacidad nuestra de captar el mundo. Esta idea nos remite a una suerte de teoría del reflejo que tiene mucha resonancia en la tradición del periodismo, al considerar al periodista como "notario" de la realidad. La verdad sería, pues, el "reflejo" de un hecho. Si bien hay una diferencia entre una teoría de la verdad como correspondencia en sentido filosófico-epistémico y la de un sentido mediático ${ }^{7}$, no debemos olvidar que esta consideración ha sido también muy cuestionada, tanto en el ámbito filosófico como en el periodístico. Entre otras cosas porque la información es una selección de hechos ${ }^{8}$, o lo que es lo mismo, una selección de mundo asociada a una señal que nos indica la ocurrencia de cierto acontecimiento.

De los múltiples modos de perfilar este apoyo filosófico para adentrarnos en el tema nuclear, nos centraremos en tres tradiciones filosóficas que pueden ayudar clarificar el perímetro informativo: positivismo, posmodernismo y perspectivismo. La clave estriba en transformar estos términos y lo que significan, en adjetivos añadidos al sustantivo periodismo.

Mientras los dos primeros modelos desembocan en una evidente impotencia (para "decir la verdad") que abre las puertas a la posverdad, el tercero no solo superará a las otras dos opciones, sino también dará una respuesta más pertinente sobre el perseguido significado de la verdad en el ámbito estudiado, teniendo en cuanta el concepto de "punto de vista".

No basta con revisar las nociones o teorías de la verdad, y las formas de justificación epistémica como guía de la verdad, sino que necesitamos comprender las implicaciones epistemológicas más amplias ${ }^{9}$. La filosofía puede ayudar,

${ }^{6}$ Catelli, Nora, "Posverdad y ficción”, en J. Ibánez Fanés y M. Arias Maldonado (coord.), En la era de la posverdad: 14 ensayos, Barcelona, Calambur, 2017, pp.139-147, p. 139.

7 Parra Pujante, Antonio, Periodismo y verdad. Filosofía de la verdad periodística, Madrid, Biblioteca Nueva, 2003, p. 25.

8 Pérez Gutiérrez, Mario, El fenómeno de la información. Una aproximación conceptual al flujo informativo, Madrid, Trotta, 2000.

9 Peters, Michael A., "Education in a post-truth world", Educational Philosophy and Theory, 49(6), 2017, pp. 563566. doi: 10.1080/00131857.2016.1264114 
sobremanera, como orientación, en la construcción de los horizontes de valor, pero no tendrá eficacia si el modo de entender el periodismo no corrige su rumbo, esto es, no reconoce los pasos que han conducido al fenómeno de la posverdad, la cual nace dentro de una metamorfosis que están sufriendo los medios de comunicación con la irrupción de internet, el ciberperiodismo y la Web Social 2.0.

\section{De la pretensión positivista a la crítica posmoderna}

El PERIODISMO EN SENTIDO POSITIVISTA entiende la verdad como objetividad de la información, donde el hecho es un acontecimiento real, objetivo y avalado documentalmente. La "verdad" se entiende, así, como la adecuación entre nuestras facultades cognoscitivas y la realidad, de ahí que la ruptura de esta relación nos conduce a una falsedad ${ }^{10}$. Por otro lado, hablar con objetividad es hablar de las cosas tal y como son por sí mismas, es decir, describir una correspondencia entre el concepto mental que nos hemos formado de la realidad y la realidad misma, y si esta no se produce, lo que expresamos es una mentira.

Este concepto "verdad" traducido al campo periodístico, sería la realidad, y la realidad no sería sino un conjunto de los hechos. Sin embargo, el primer Wittgenstein seńaló que el mundo está determinado por los hechos porque estos son todos los hechos ${ }^{11}$. Y es dicha totalidad la que estipula lo que es y lo que no es real. Si seguimos al pie de la letra esta idea, los medios de información tendrían que referir únicamente aquellos hechos que interesan al público lector, bien porque afectan a sus intereses o porque exciten su curiosidad ${ }^{12}$.

Esta problemática ya la percibió W. Lippmann al observar la complejidad de una sociedad que solo alcanza a entrever de manera incompleta y distorsionada la realidad $^{13}$. Ni los ciudadanos son omnicompetentes, ni los informadores pueden suplir las limitaciones de información que lastran a la opinión pública.

Por consiguiente, la señalada verdad-objetiva tiene muchas dificultades no solo para hacerse realidad, sino para convertirse en una aspiración. Es la conclusión que, de alguna manera, llega el pensamiento posmoderno. Un pensamiento que al mismo tiempo que cuestiona el objetivismo, lo hace con el equivalente periodístico: hechos, verificación, publicación, reacción y nuevos hechos.

${ }^{10}$ Echaniz, Arantza y Pagola, Juan, Ética profesional de la comunicación, Bilbao, Desclée de Brouwer, 2004, p. 63.

11 Wittgenstein, Ludwig, Tractatus lógico-philosophicus, Madrid, Tecnos, 2007.

12 Montoya, José, "Ética de la información”, Iglesia viva, 155, 1991, pp. 491-496, p. 493.

13 Lippmann, Walter, Opinión pública, Madrid, Cuadernos de Langre, 2003. 
Recordemos que el pensamiento posmoderno, del que se nutren algunos sectores del periodismo, proviene de la crítica a la modernidad desde diversos ángulos. Uno de ellos es la consideración de la Verdad como uno de los grandes relatos que provienen de la ilustración, y que, según J.F. Lyotard, son tan imposibles como innecesarios ${ }^{14}$.

Dicha verdad como representación también queda imposibilitada desde la configuración de la filosofía del lenguaje desarrollada por el segundo Wittgenstein y su advertencia: no es el sujeto, con sus experiencias e intenciones, la fuente del significado lingüístico ${ }^{15}$. Igualmente, podemos añadir la aversión a toda fundamentación que defiende G. Vattimo, y su contraposición con la multiplicación de las "agencias interpretativas" ${ }^{16}$. Críticas todas ellas que conducen a una Roma: la destrucción de la idea de un sujeto autónomo que, desde la razón, identifique los objetos por medio de conceptos.

Más allá de los aspectos concretos que tienen sus "razones", el resultado es que la posmodernidad ha posibilitado un ambiente cargado de ambigüedad por todas partes. O como indica V. Gozálvez, la posmodernidad ha cambiado el sentido de la experiencia, pero no solo ha introducido tolerancia, diversidad y respeto, sino también un pensamiento debilitado, un desencanto hacia lo público y lo social, que se nutre de una mirada relativa: la verdad se ha personalizado ${ }^{17}$. O, en todo caso, "solo es cierto para un grupo concreto de personas, en ciertos contextos o ciertos sentidos" ${ }^{18}$. Este relativismo se legitima periodísticamente mediante una idea repetida: lo mejor es ofrecer todas las versiones, y que cada lector, u oyente, elija.

La conclusión a lo dicho nos la ofrece V. Camps: "dado que la verdad no es monopolio de nadie, que es prácticamente inalcanzable, dado que los puntos de vista son diversos y plurales, puesto que estamos en la era del pensamiento débil y la sociedad líquida, ¿a qué viene preocuparse por buscar la verdad?” ${ }^{19}$. Se nos presenta el siguiente dilema: ¿dejamos de buscar dicha verdad, o seguimos indagando sobre esta como base de la información? Si nos quedamos en lo primero, es natural que acabemos hablando de posverdad.

${ }^{14}$ Lyotard, Jean-François, La condición postmoderna. Informe sobre el saber, Madrid, Cátedra, 1991, pp. 9-11.

15 Wittgenstein, Ludwig, Tractatus lógico-philosophicus, Madrid, Tecnos, 2007.

${ }^{16}$ Vattimo, Gianni, "Post-modernidad, tecnología, ontología", en F. Jarauta, (ed.), Otra mirada sobre la época, Murcia, Colegio Oficial de Aparejadores y Arquitectos, 1994, p. 81.

${ }_{17}$ Gozálvez, Vicent, Educación para una ciudadanía mediática. Una mirada educativa. Madrid, Dykinson, 2012

18 Baggini, Julian, Breve historia de la verdad, Barcelona, Ático de Los Libros, 2018.

19 Camps, Victoria, "Posverdad, la nueva sofística”, en J. Ibáñez Fanés y M. Arias Maldonado (coord.), En la era de la posverdad: 14 ensayos, Barcelona, Calambur, 2017, pp. 91-100, p. 95. 


\section{Lo que la posverdad esconde}

PARA Un PRIMER ACERCAMIENTo al significado básico de la posverdad, podemos decir que post-truth apela a las emociones y a las creencias que influyen más en la formación de la opinión pública que los hechos objetivos. Según nuestra consideración, posverdad es diferente a mentira, ya que su objetivo es rematar la idea de verdad posmoderna, y definitivamente deshacerse del peso de la verdad en todos los sentidos. La posverdad no solo expone una mentira, sino también una noticia falsa (fake news). Es, por tanto, algo más que la mentira, ya que la mentira puede llegar a descubrirse; pero la posverdad se inmuniza o trata de no precisar la corroboración con hechos. Es un desvío del ideal de verdad, por lo que la "no verdad" ya no se produce por la imposibilidad de un periodismo positivo o por la asumida impotencia del periodismo posmoderno, sino que se convierte en una aspiración. Esto es lo que la posverdad esconde.

Este fenómeno lo ha denominado H. Frankfurt con el término "bullshit" ${ }^{20}$. Si bien el mentiroso es consciente del peso de la verdad, también lo es de su mentira. Por otro lado, el "bullshitter" no está ni del lado de la verdad ni del lado de la mentira. Tampoco le importa si lo que se narra describe la realidad, más bien la inventa, para alcanzar su propósito: persuadir de un aparente hecho, es decir, la realidad a la carta.

Afinando todavía más, post-truth invoca más a las emociones y a las creencias que a los hechos comprobables ${ }^{21}$. Es, por tanto, una deformación meditada de una realidad, con el fin de influir a la opinión pública. Lo cual hace saltar todo indicio de los hechos ya que la distorsión de la realidad se ejecuta apelando a creencias de los ciudadanos, a los que en muchas ocasiones no les importa dicha distorsión de la realidad si favorece a sus creencias o a sus intereses. Lo que se persigue no es tampoco la desinformación, sino el hedonismo cognitivo como mejor modo de enfrentarse al imposible objetivismo. Es, en fin, el resultado final del desmoronamiento de los grandes relatos.

Lo que está en juego con la posverdad es qué explicación nos creemos para entender el mundo. O más aun, "la falsedad se convierte en verdad por la fuerza de la identificación emocional" 22 . Llegados a este punto, aparece el tema de la manipulación, ya que con la posverdad se agudiza la fabricación de pistas falsas, y al

\footnotetext{
${ }^{20}$ Frankfurt, Harry, On Bullshit. Princeton, N.J., Princeton University Press, 2005.

${ }_{21}$ Ibánez, Jordi, "La posverdad no es mentira”, en J. Ibáñez Fanés y M. Arias Maldonado (coord.), En la era de la posverdad: 14 ensayos, Barcelona, Calambur, 2017, pp. 37-48.

22 Arias Maldonado, Manuel, “Informe sobre ciegos: genealogía de la posverdad”, en J. Ibánez Fanés y M. Arias Maldonado (coord.), En la era de la posverdad: 14 ensayos, Barcelona, Calambur, 2017, pp. 65-77, p. 67.
} 
mismo tiempo, genera la sensación de seguridad cuando solo se ofrece una ilusión de orientación, una satisfacción emotiva, una falsa sensación de libertad. Esta apreciación es diferente al cliché de que los medios son subjetivos, porque todavía en este juicio la honestidad mantiene una posición predeterminada. Y esta expectativa se diluye en un mundo pos-verdad, es decir, en una verdad emocional porque quien la pronuncia y quien la escucha están convencidos de que es auténtica, aunque los hechos demuestren lo contrario ${ }^{23}$.

Vemos, pues, necesario buscar respuestas filosóficas para encontrar una salida a la dicotomía abierta por el periodismo positivo y el posmoderno sin terminar en una posverdad que no niega la verdad, pero tampoco la considera prioritaria. De lo contrario estaremos dando razón a $\mathrm{H}$. Arendt cuando sostenía que la mentira ya no es un proceso subjetivo, sino un proceso sistémico de la política y de los medios ${ }^{24}$.

\section{Verdad y"puntos de vista"}

ESTE APARTADO SURge POR LA SEÑALADA NECESIDAD concerniente a la discusión examinada, para lo cual revisamos la tradición perspectivista (Nietzsche y Ortega y Gasset), porque creemos que no solo nos retrotrae el problema de la verdad filosófica, sino que también conlleva grandes repercusiones relativas a la verdad periodística. Porque, ¿qué preferimos, una información aparentemente neutra o un periodista que honestamente, verazmente, describe, informa, sin obviar su punto de vista? Recurrimos a ambos filósofos para elucidar la relación entre el "punto de vista" y la verdad y la posibilidad de compatibilidad.

\subsection{Genealogía, perspectivismo y critica del anbelo de verdad en Nietzsche}

TAMbiÉn la POSMODERNidAd FILOSÓfica cita como su antecedente la crítica de Nietzsche a la cultura occidental, concentrándose en la indagación genealógica que desestabiliza los cimientos morales y culturales que damos por seguros, pero quizás obviando el proyecto de transvaloración inherente a la misma ${ }^{25}$. Si bien admitimos

\footnotetext{
${ }^{23}$ Higgins, Kathleen, "Post-truth: a guide for the perplexed", Nature, 590, 2016, 9. Cebrián, Juan Luis, "Del posmodernismo a la posverdad”, El País, 22.06.2019. Disponible en: https://elpais.com/cultura/2019/06/20/ babelia/1561029028_972307.html

24 Arendt, Hannah, Verdad y mentira en la politica, Madrid, Página Indómita, 2007.

25 Para una valoración crítica, véase Heit, Helmut, “there are no facts...': Nietzsche as Predecessor of Post-truth?”, Studia Philosophica Estonica, 11(1), 2018, 44-63: doi: 10.12697/spe.2018.11.1.03, donde además se analiza a Kant, Schopenhauer, Lange y Guyau como fuentes de esta comprensión crítica sobre los límites de la verdad.
} 
la valoración de la crítica nietzscheana de la Modernidad, consideramos que su filosofía no ha sido claramente comprendida por los pensadores posmodernos, ni siquiera por Vattimo, cuando asevera que "la genealogía es fluidificar, historizar el presente permitiendo la apertura a nuevas posibilidades trascendentes al mismo" ${ }^{26}$. Es posible interpretar, por otro lado, que criticar la Modernidad, discernirla, seleccionarla, significa, en última instancia, convertirse en su mejor abogado. Además, son muchos los especialistas que han argumentado contra el uso y abuso de Nietzsche por parte de la postmodernidad filosófica ${ }^{27}$, y contra las confusiones conceptuales de quienes ven en Nietzsche un relativismo y subjetivismo irracional incapaz de evaluar y dar respuesta al problema de la jerarquización del conocimiento, de la moral, la política, la estética y la evaluación global de las culturas ${ }^{28}$.

Este es un tema crucial y complejo de los estudios nietzscheanos, por ello, sin ningún ánimo de exhaustividad, en lo que sigue argumentaremos en los parámetros que nos son posibles en este artículo, que el perspectivismo en Nietzsche no puede asimilarse al relativismo en su comprensión más vulgar ${ }^{29}$. El anhelo de verdad absoluta es sustituido en Nietzsche por el método genealógico y el perspectivismo, que funcionan bajo el soporte de una noción de verdad situada, relacional, una verdad condicionada y posibilitada por nuestro propio aparato de conocimiento, es decir, nuestra fisiología, que es cambiante. Los seres vivos deben interactuar con el mundo, formando creencias y valoraciones sobre lo peligroso, lo seguro, lo comestible, lo venenoso, lo bueno, lo malo, por ello, todo lo que vive, selecciona información, la valora, y por tanto, interpreta ${ }^{30}$. Desde Humano, demasiado humano reconoce esta situación de crisis de los valores antaño tenidos por sagrados e inmutables como un resultado positivo del despliegue de la razón moderna: la crítica del dogmatismo, la imposibilidad de anular las perspectivas o reducirlas a una sola, como única válida y verdadera. En esa misma obra, Nietzsche presenta una variedad de estándares y actitudes epistémicas con respecto a la ciencia, la convicción y la prudencia, que distinguen su postura de

\footnotetext{
${ }^{26}$ Vattimo, Gianni, El sujeto y la máscara, Barcelona, Península, 1989, p. 137.

27 A modo de ejemplo, Gemes, Ken, "Postmodernism's Use and Abuse of Nietzsche”, Philosophy and Phenomenological Research, 62(2), 2001, pp. 337-360. doi: 10.1111/j.1933-1592.2001.tb00059.x

28 Stellino, Paolo \& Tinland, Olivier (dir.), Nietzsche et le relativisme, Bruxelles, Ousia, 2019.

29 De hecho, Nietzsche nombra bajo un mismo paraguas «la posición escéptica o relativista» (Humano, demasiado humano \$631, MA-631, OC III p. 268). Los textos de Nietzsche se citan indicando las siglas normalizadas en alemán de la edición crítica digital (eKGWB) elaborada por el profesor Paolo D’lorio, que mantiene el sistema de siglas establecido desde la edición académica de Colli-Montinari. Añadiendo estas siglas a la dirección www. nietzschesource.org/\#eKGWB/, obtendremos un enlace que nos mostrará ese pasaje en la eKGWB, disponible en libre acceso. En el cuerpo del artículo se emplean las traducciones al español de las ediciones de Obras Completas (OC) y Fragmentos Póstumos (FP), elaboradas bajo la dirección de Diego Sánchez Meca y publicadas en la editorial Tecnos. Se indica el volumen en números romanos, seguido de las páginas citadas.

${ }^{30}$ Heit, Helmut, “'there are no facts...': Nietzsche as Predecessor of Post-truth?”, op. cit., p. 56.
} 
cualquier visión relativista simplificada ${ }^{31}$, y que en su lugar, le lleva a afirmar "lo perspectivista, que es la condición fundamental de toda la vida" ${ }^{32}$, al servicio de una reforma de la cultura que eleve la vida.

Los elementos del proceso genealógico que Nietzsche esboza en De la genealogía de la moral descalifican toda idea de lo absoluto, ya sea en un sentido ontológico, como existencia de realidades en sí, o en un sentido gnoseológico, como existencia de verdades objetivas, y establece en su lugar el carácter interpretativo de la realidad $^{33}$. En su comprensión crítica de la filosofía, Nietzsche insiste en que el método tradicional de la búsqueda de la verdad representacional descuida la presencia más profunda de un condicionamiento de las ideas y de los modos de pensar, que varía en cada cultura y que opera a través de los valores ${ }^{34}$. No ampara una indiferencia arbitraria ni ante el valor ni ante el valor, sino que es necesario situar y analizar cada creencia como "algo relativamente valioso (Relativ-Werthvolles) que admite pros y contras, el sopesar y distinguir" ${ }^{35}$.

Según la narrativa de la génesis del lenguaje que Nietzsche expone en Sobre verdad y mentira en sentido extramoral ${ }^{36}$, con el objetivo de posibilitar la vida en sociedad, se impone como norma a todos los miembros del grupo la obligación de emplear unas designaciones lingüísticas establecidas por convención. Para sobrevivir, el ser humano desarrolla órganos de conocimiento. Para conservar, esquematiza e inventa, simplifica, generaliza. De esta manera surge la idea de verdad y desde esta perspectiva, la verdad es un valor, ensalzado por la sociedad. Pero esta forma de proceder tiene como consecuencia el olvido de otras no-verdades, otras posibilidades, otras metáforas. Cuando las personas desarrollan juicios a propósito de sí mismos y de los demás, no se percatan de lo que es contingente, de sus manipulaciones de lo falso, de sus errores. Tanto los racionalistas como los empiristas creen que el sujeto del conocimiento busca captar un objeto tal y como es. Nietzsche, en cambio, concibe el mundo en un perpetuo

\footnotetext{
31 Véase en Humando, demasiado humano, del aforismo $\$ 630$ en adelante, MA-630, OC III pp. 267 ss.

32 Más allá del bien y del mal "Prólogo" (JGB-Vorrede), OC IV p. 239.

33 Wotling, Patrick, "Génealogie (Genealogie)", en D. Astor (dir.), Dictionnaire Nietzsche, Paris, Laffont, 2017, pp. 368-373.

34 Así lo expresa concretamente en el célebre fragmento póstumo 7[60] de 1886: "Contra el positivismo, que se queda en el fenómeno «sólo hay hechos», yo diría no, precisamente no hay hechos, sólo interpretaciones. No podemos constatar ningún factum "en sî": quizás sea un absurdo querer algo así. "Todo es subjetivo", decís vosotros, pero ya eso es interpretación. (...) En la medida en que la palabra "conocimiento" tiene sentido, el mundo es cognoscible: pero es interpretable de otro modo, no tiene un sentido detrás de sí, sino innumerables sentidos, "perspectivismo". Son nuestras necesidades las que interpretan el mundo: nuestros impulsos y sus pros y sus contras. Cada impulso es una especie de ansia de dominio, cada uno tiene su perspectiva, que quisiera imponer como norma a todos los demás impulsos". (NF-1886,7[69], FP IV, p. 222).

35 Opiniones y sentencias diversas $\$ 305$ (VM-305), OC III p. 352. Trad. ligeramente modificada.

36 Sobre verdad y mentira en sentido extramoral (VL), en OC I, pp. 609-619.
} 
devenir y niega la existencia de un mundo del ser. Por ello, desplaza la tarea de la filosofía en su búsqueda de la verdad, del terreno epistemológico al terreno de la axiología ${ }^{37}$.

La búsqueda de la verdad se explica como medio de conservación de las personas, como voluntad de poder ${ }^{38}$. De ahora en adelante, la tarea consiste en cuestionar las apreciaciones valorativas que se esconden tras esta voluntad de verdad. Si la experiencia es la base de apertura al mundo, "esto implica un carácter necesariamente valorativo que imposibilita un acceso objetivo, neutral, a la verdad" 39 . En su lugar, aboga por un conocimiento no desvinculado de la orientación de la acción, el "cultivo intelectual para la 'objetividad' venidera, — entendida esta última no como "contemplación desinteresada" (...), sino como "la facultad de tener poder sobre los pros y los contras y saber aportarlos y retirarlos", y "aprovechar para el conocimiento la diversidad de perspectivas e interpretaciones de los afectos" ${ }^{40}$. La objetividad no se alcanza eliminando el elemento personal, sino que se transvalora y se alcanza llegando a ver las cosas como las ven cien ojos, desde "muchos ojos y muchas miradas absolutamente personales" ${ }^{11}$. A partir de dicho cúmulo de perspectivas, se puede elaborar un conocimiento con pretensión de objetividad, pero despojado de cualquier aparato metafísico que le confiriese una autoridad extramoral.

No es posible, pues, un conocimiento universalmente compartido de las cosas. Pero desplazar la pregunta por la verdad al interrogante por el valor de la verdad no implica que todo valga, que todo dé igual. Nietzsche detesta la verdad representacional, y, sobre todo, el anhelo de sostén de quien necesita la certeza de la verdad absoluta. "El pathos de la posesión de la verdad vale muy poco en comparación a ese otro pathos, sin duda más suave y callado, de la búsqueda de la verdad, el que nunca se cansa de aprender y experimentar cosas nuevas» ${ }^{42}$, es decir, que no quiere encontrar la verdad para poseerla, quiere seguir buscándola. Por esto también, el «pensador que se define como un genio", que «toma la actitud de hombre superior al cual le corresponde la autoridad» es en realidad, «un enemigo de la verdad» ${ }^{43}$. La cuestión no es qué es la verdad, sino situar esa pregunta en el nivel de la tonalidad afectiva, en el contexto de la creación del valor, porque quizás no es la verdad poderosa, iluminadora o liberadora. Por ello, la perspectiva nietzscheana lanza el su-

\footnotetext{
${ }^{37}$ Marton, Scarlett, "Vérité (Wahrheit)”, en D. Astor (dir.), Dictionnaire Nietzsche, Paris, Laffont, 2017, pp. $917-$ 922.

38 NF-1884,25[470], FP III p. 534.

39 Romero Cuevas, José Manuel, "Perspectivismo y crítica social. De Nietzsche a la Teoría Crítica”, Logos. Anales del Seminario de Metafísica, 48, 2015, pp. 141-163, p. 142. doi: 10.5209/rev_ASEM.2015.v48.49278

40 De la genealogía de la moral III \$12 (GM-III-12), OC IV p. 529.

${ }^{41}$ NF-1881,11[65], FP II pp. 772-773.

${ }^{42}$ MA-633, OC III p. 269.

43 MA-635, OC III p. 270.
} 
gerente desafío de construir lentes capaces de captar las fuerzas que rigen la cultura y el orden de los valores.

Se trata de una crítica del estatus epistémico privilegiado otorgado a conceptos como "cosa en sî", "verdad", "hecho", "realidad", y su carácter de "dado", que son el producto de una perspectiva que ya está impregnada de estimaciones de valor, precisamente por su ser perspectiva ${ }^{44}$. Nietzsche instaura la interpretación, no como explicación, sino como figura básica del pensamiento responsable de la introducción de sentido, y esto no significa en absoluto que no podamos o debamos escoger entre una pluralidad de puntos de vista. La dificultad, o la nueva tarea, estribaría en realizar una jerarquía de interpretaciones, que se aprecia también en su constante apelación a la filología y al arte de "leer bien": "poder leer los hechos sin falsearlos con la interpretación, sin perder, por deseo de entenderlos, la precaución, la paciencia, la sutileza" ${ }^{45}$.

Es precisamente en esta limitación crítica del conocimiento donde reside según Nietzsche el amor de la tragedia, pues la tragedia se revela como el lugar de dos movimientos cruzados y contradictorios, lo que nos obliga a pensar en la consideración de Nietzsche del conflicto permanente, y, por tanto, con un sentido agonal ${ }^{46}$. En el fondo de lo tratado se encuentra el hecho de que lenguaje es esencialmente metafórico. Y esta idea rompe con una verdad, pero abraza "otra verdad", esto es, refuerza otra valoración al servicio de la elevación de la cultura y de la vida, y no su abandono en el nihilismo o el relativismo. Y la clave de todo, es el sentido, el hacía dónde y el para qué, que es creado y reforzado, en el mismo proceso de interpretar.

Lo verdadero no surge del punto de vista permanente y seguro, sino que la disyuntiva es hundirse en las raíces de libertad para introducirse en el mundo de la perspectividad. Somos prisioneros de nuestro aparato sensorial, de la fisiología de los sentidos: de ahí nacen nuestros juicios de valor, pero las perspectivas son valiosas. Ahora bien, no se trata de alcanzar una "verdad objetiva" sino una "verdad de sentido" ${ }^{47}$. La transvaloración no implica relativismo, sino que busca el modo de "comprender mejor". La crítica de la razón no supone, por tanto, el abandono de la misma, como vimos en la crítica posmoderna, sino abrirse a una razón impura. La noción de razón no se devalúa, sino que se amplia. Lo mismo hace Ortega y Gasset con su "razón vital".

\footnotetext{
${ }^{44}$ García-Granero, Marina, "La transvaloración de las perspectivas. Nietzsche y la crítica de la cultura desde el punto de vista del valor", Daimon, 75, 2018, pp. 161-176. doi: 10.6018/daimon/334461

45 El Anticristo $\$ 52$, AC-52, OC IV p. 755.

${ }^{46}$ Herreras, Enrique, La tragedia griega y los mitos democráticos, Madrid, Biblioteca Nueva, 2010.

${ }^{4}$ Conill, Jesús, El poder de la mentira. Nietzsche y la politica de la transvaloración, Madrid, Tecnos, 1997, p. 74.
} 


\subsection{Ortega y Gasset y la realidad dramática}

Como dice Ortega, "bajo el nombre de 'verdad' se oculta un problema sumamente dramático" ${ }^{48}$ que puede resumirse en que solo alcanzamos una porción de verdad, un "punto de vista". A partir de aquí, el filosofó madrileño ve dos caminos filosóficos erróneos: por un lado, el racionalismo para salvar la verdad renuncia a la vida, y, por otro, el relativismo salva la vida evaporando la razón ${ }^{49}$. Por ello, el tema de nuestro tiempo consiste en someter a la razón a la vitalidad ${ }^{50}$. Así es, la captación de la realidad por parte del ser humano se produce desde la perspectiva vital en la que nos hallamos situados. Una perspectiva que es falsa cuando pretende ser única. Para Ortega, dar cuenta cabal de la realidad es darla desde la perspectiva en la que cada uno está. Pero, más que quedarse en la disputa de perspectivas individuales, la diversidad de perspectivas es la que hace posible, en cuanto es complementaria la variedad de las perspectivas, una mayor objetividad sobre la realidad y la verdad. La explicación estriba en la superación del idealismo y el subjetivismo mediante el raciovitalismo.

Lo concluyente, para nuestro tema, se encuentra en la consideración de Ortega relativa a la faena de pensar, que no es otra cosa que una reacción ante una realidad presente previa. Empleando los términos de Ortega, podríamos decir que el periodista padece la circunstancia, se nutre con la realidad a partir del yo abriéndose y padeciendo la realidad que es el contorno. Así, "la perspectiva es uno de los componentes de la realidad" 51 .

El alcance de todo ello lo presenta J. Conill al describir una biohermenéutica desde una razón que denomina "experiencial", enraizada en la intimidad del cuerpo humano ${ }^{52}$. En definitiva, este conflicto tiene que ver con el peligro de la autodestrucción de la razón, y también con el peligro de coerción epistemológica del positivismo. Desde esas premisas, "se puede alumbrar una tercera posibilidad: la que media lógos y experiencia en la razón experiencial" y así, "la misma formalidad que hace posible una cierta distancia o apertura, se nutre del contenido experiencial" 53 .

Existen, pues, respuestas ante las señaladas posiciones sobre la dificultad de la verdad que nos conduce tanto el periodismo positivista como el posmoderno. La

\footnotetext{
48 Ortega y Gasset, José, “El tema de nuestro tiempo”, en Obras Completas III, Madrid: Alianza, 1983, pp. 145203, p. 157.

49 Ortega y Gasset, José, "Relativismo y racionalismo”, en Obras Completas III. Madrid: Alianza, 1983, pp. $157-$ 162 , p. 162.

50 Ortega y Gasset, José, "El tema de nuestro tiempo”, op. cit, p. 178.

51 Gracia Calandín, Javier, "La perspectiva intercultural: Ortega y la hermenéutica”, Daimon. Revista internacional de Filosofia, 75, 2018, pp. 147-160, p. 151. doi: 10.6018/daimon/335731

52 Conill, Jesús, Intimidad corporal y persona humana. De Nietzsche a Ortega y Zubiri, Madrid, Tecnos, 2019.

53 Conill, Jesús, Ética hermenéutica, Madrid, Tecnos, 2006, pp. 276-277.
} 
revisión del perspectivismo filosófico nos ayuda, como hemos visto, a intermediar entre la dicotomía entre periodismo objetivista y posmoderno, desde una perspectiva o aproximación bien diferente de la posverdad. Con el perspectivismo, desde la interpretación descrita, no hay impotencia ni imposibilidad de la verdad, porque es la verdad la que se entiende de otra manera. Para Nietzsche, como hemos visto, solo en la senda de la interpretación algo se convierte en hecho, por lo que dicha interpretación no es un recurso complementario del conocimiento, sino que constituye su estructura originaria, el subsuelo de lo invisible y lo oculto.

\section{Conclusiones}

LA FILOSOfía PUEDE APORTAR LUZ a los dilemas del periodismo, pero esto no significa, como se ha dicho, que la profesión periodística no tenga que habérselas con sus problemas concretos, aquellos que ayudan a distorsionarla, como los que brotan de intereses empresariales y sesgos ideológicos.

La nueva realidad empresarial es, aquí y ahora, un proceso inconcluso del que no se sabe muy bien hacia dónde va, sobre todo a partir del desarrollo de las redes sociales que plantea situaciones ambivalentes. Se dice que internet es el reino de la mentira, pero también de la libertad. Por un lado, la red multiplica la capacidad de opinar de mucha gente al abrir espacios alternativos. En concreto, hay quien habla de "periodismo ciudadano" o de "democracia monitorizada" ${ }^{4}$ al posibilitar la Red la participación de los ciudadanos, lo cual va en consonancia con la demanda de Cortina de promover poliarquías, esto es, multiplicar los centros de poder (¿los "puntos de vista"?), frente a los monopolios de la comunicación ${ }^{55}$. Desde una perspectiva no tan positiva, habría que considerar que las nuevas tecnologías están produciendo una especie de descentralización, interactividad e individualismo ${ }^{56}$ y que "el poder va más allá de la comunicación, y la comunicación va más allá del poder, pero el poder consiste en el control de la comunicación" ${ }^{57}$.

Pero, aun así, habría que percibir que el punto de vista no es una limitación, sino una clarividencia del acceso a una verdad que puede seguir siendo una meta, porque si la ciudadanía no puede distinguir la noticia falsa de la verdadera, sus decisiones se quedan a la intemperie de una realidad deformada y supuesta.

\footnotetext{
54 Keane, John, The life and death of democracy, London, Simon \& Schuster, 2009.

55 Cortina, Adela, "Ciudadanía activa en una sociedad mediática", en J Conill y V. Gozálvez (eds.), La ética de los medios, Barcelona, Gedisa, 2004, pp. 11-31.

56 Castells. Manuel, La era de la información: economía, sociedad, cultura (I), Madrid, Alianza, 1997, p. 390.

57 Castells, Manuel, Comunicación y poder, Madrid, Alianza, 2009, p. 20.
} 
Tener un punto de vista, como se ha tratado de demostrar, no es una ocurrencia, ni un invento (realidad inventada), sino un punto de partida dentro de un horizonte social y una tentativa hacia una mejor comprensión, es decir, una articulación del sentido. Se precisan, por tanto, buenos intermediarios que nos muestren una visión coherente de la realidad, "la selección extraordinaria de la realidad" 58 , y que, al mismo tiempo, contrarresten las mentiras y los datos irrelevantes y, por ende, desinformadores.

Por ello, la responsabilidad para poder infundir confianza cobra un papel significativo, porque, en gran medida, la construcción de la voluntad política se nutre de la verdad o falsedad de la información, de sus puntos de vista, en definitiva. Y dado que la verdad positivista es inalcanzable en un sentido estricto, el cuestionamiento de la filosofía y del periodismo no debe orientarse únicamente por el objetivo de la voluntad de veracidad, sino que se ha de atender también la esfera de los valores, el tipo de cultura y de sociedad que convendría promover y construir en común. En el contexto de la ética del periodismo ${ }^{59}$, la cuestión clave deviene hacia qué tipo de sociedad — nihilista caminamos cuando la verdad, situada, consensuada, deja de ser un valor para la vida.

En realidad, la posverdad nos distrae de algo más alarmante que la intencionada deformación de la realidad: "la propia incapacidad de los sujetos para hacerse cargo de la complejidad informativa del mundo" ${ }^{60}$.

Recapitulando lo seńalado anteriormente, el periodista que sigue fiel a la verdad, desde la percepción perspectivista que hemos visto, debiera ser consciente de que la metáfora es lo que enriquece nuestra experiencia real.

Esta actitud conlleva seguir indagando y defendiendo la verdad del periodismo dada su repercusión social y sus consecuencias en la estrecha relación que hay entre opinión pública, opinión publicada y la democracia —el surgimiento de la política de la posverdad coincide con las creencias políticas polarizadas. A la postre, los fines que dan sentido y legitimidad social a la actividad mediática son fines específicos suyos, que se resumen en la tarea de colaborar en formar una opinión pública madura - "el buen uso público de la razón", que diría Kant ${ }^{61}$ —, un objetivo en el que difícilmente cabe la posverdad, que ya podemos sintetizar como una devaluación nihilista del valor de la verdad. Pero, para superar esto hace falta un "esfuerzo por la verdad", o mejor, el "coraje de la verdad" (Foucault), lo que conlleva asuntos que están en el ADN del periodismo como la verificación fáctica, la contrastación, o el balance de fuentes contradictorias.

\footnotetext{
58 Sinova, Justino, "Periodismo", en A. Cortina y J. Conill (dir.), 10 palabras clave en ética de las profesiones, Estella, Verbo Divino, 2000, pp. 257-286, p. 278.

59 Herreras, Enrique, "Experiencia profesional y ética del periodismo de opinión”, Dilemata, 2014, 14, pp. 141162.

${ }^{60}$ Innerarity, Daniel, Política para perplejos, Barcelona, Galaxia Gutenberg, 2018, p. 33.

${ }^{61}$ Cortina, Adela, "Ciudadanía activa en una sociedad mediática”, op. cit., p. 11.
} 


\section{REFERENCIAS Bibliográficas}

Arendt, Hannah, Verdady mentira en la politica, Madrid, Página Indómita, 2007.

Arias Maldonado, Manuel, "Informe sobre ciegos: genealogía de la posverdad", en J. Ibáñez Fanés y M. Arias Maldonado (coord.), En la era de la posverdad: 14 ensayos, Barcelona, Calambur, 2017, pp. 65-77.

Baggini, Julian, Breve historia de la verdad, Barcelona, Ático de Los Libros, 2018.

Berger, Peter y Luckmann, Thomas, La construcción social de la realidad, Buenos Aires, Amorrortu, 2006.

Camps, Victoria, "Posverdad, la nueva sofística", en J. Ibáńez Fanés y M. Arias Maldonado (coord.), En la era de la posverdad: 14 ensayos, Barcelona, Calambur, 2017, pp. 91-100.

Castells, Manuel, La era de la información: economía, sociedad, cultura (I), Madrid, Alianza, 1997.

Castells, Manuel, Comunicación y poder. Madrid: Alianza, 2009.

Catelli, Nora, "Posverdad y ficción", en J. Ibáñez Fanés y M. Arias Maldonado (coord.), En la era de la posverdad: 14 ensayos, Barcelona, Calambur, 2017, pp.139-147.

Cebrián, Juan Luis, "Del posmodernismo a la posverdad", El País, 22.06.2019. Disponible en: https://elpais.com/cultura/2019/06/20/babelia/1561029028_972307.html

Conill, Jesús, El poder de la mentira. Nietzsche y la politica de la transvaloración, Madrid, Tecnos, 1997.

Conill, Jesús, Ética hermenéutica. Critica desde la facticidad, Madrid, Tecnos, 2006.

Conill, Jesús, "Una lectura hermenéutica de la filosofía orteguiana", en J. Zamora, J. (ed.). Guia Comares de Ortega y Gasset, Granada, Comares, 2013, pp. 207-221.

Conill, Jesús, Intimidad corporal y persona humana. De Nietzsche a Ortega y Zubiri, Madrid, Tecnos, 2019.

Cortina, Adela, "Ciudadanía activa en una sociedad mediática", en J Conill y V. Gozálvez, (eds.), La ética de los medios, Barcelona, Gedisa, 2004, pp. 11-31. 
Cortina, Adela, "Periodismo imprescindible", El País, 29.01.2018. Disponible en: https://elpais.com/elpais/2018/01/26/opinion/1516968330_170402.html

D'Ancona, Matthew, Post Truth. The New War on Truth and How to Fight Back. London, Ebury Press, 2017. Traducción española: Posverdad. Madrid, Alianza.

Echaniz, Arantza y Pagola, Juan, Etica profesional de la comunicación, Bilbao, Desclée de Brouwer, 2004.

Ferraris, Maurizio, Postverità e altri enigmi, Bologna, Il Mulino, 2017.

Frankfurt, Harry, On Bullshit, Princeton, N.J., Princeton University Press, 2005.

García-Granero, Marina, "La transvaloración de las perspectivas. Nietzsche y la crítica de la cultura desde el punto de vista del valor", Daimon, 75, 2018, pp. 161-176. doi: 10.6018/daimon/334461

Gemes, Ken, "Postmodernism's Use and Abuse of Nietzsche", Philosophy and Phenomenological Research, 62(2), 2001, pp. 337-360. doi: 10.1111/j.19331592.2001.tb00059.x

Gracia Calandín, Javier, "La perspectiva intercultural: Ortega y la hermenéutica, Daimon. Revista internacional de Filosofía, 75, 2018, pp. 147-160. doi: 10.6018/ daimon/335731

Gozálvez, Vicent, "Los relatos del mundo: entre la objetividad y la imparcialidad", en Jesús Conill y Vicent Gozálvez (coord.), La ética de los medios, Barcelona, Gedisa, 2004, pp. 79-109.

Gozálvez, Vicent, Educación para una ciudadanía mediática. Una mirada educativa. Madrid, Dykinson, 2012.

Heit, Helmut, "'there are no facts...': Nietzsche as Predecessor of Post-truth?", Studia Philosophica Estonica, 11(1), 2018, pp. 44-63. doi: 10.12697/ spe.2018.11.1.03

Herreras, Enrique, La tragedia griega y los mitos democráticos, Madrid, Biblioteca Nueva, 2010.

Herreras, Enrique, "Experiencia profesional y ética del periodismo de opinión", Dilemata, 2014, 14, pp. 141-162.

Higgins, Kathleen, "Post-truth: a guide for the perplexed", Nature, 590, 2016, 9.

Honneth, Axel, El derecho de la libertad. Esbozo de una eticidad democrática. Madrid, Katz Editores, 2014. 
Ibáñez, Jordi, "La posverdad no es mentira”, en J. Ibáñez Fanés y M. Arias Maldonado (coord.), En la era de la posverdad: 14 ensayos, Barcelona, Calambur, 2017, pp. 37-48.

Innerarity, Daniel, Politica para perplejos, Barcelona, Galaxia Gutenberg, 2018.

Keane, John, The life and death of democracy, London, Simon \& Schuster, 2009.

Kovach, Bill; Rosenstiel, Tom, Los elementos del periodismo, Madrid: Santillana. 2012.

Lippmann, Walter, Opinión pública, Madrid, Cuadernos de Langre, 2003.

Lyotard, Jean-François, La condición postmoderna. Informe sobre el saber, Madrid, Cátedra, 1991.

Marton, Scarlett, "Vérité (Wahrheit)", en D. Astor (dir.), Dictionnaire Nietzsche, Paris, Laffont, 2017, pp. 917-922.

Montoya, José, "Ética de la información”, Iglesia viva, 155, 1991, pp. 491-496.

Nietzsche, Friedrich, Digitale Kritische Gesamtausgabe, Werke und Briefe [eKGWB], Paris, Nietzsche Source, 2009 ss. Herausgegeben von Paolo D'Iorio. Disponible en www.nietzschesource.org/\#eKGWB

Nietzsche, Friedrich, Fragmentos Póstumos. Madrid: Tecnos, 2006-2010, 4 vols. Edición dirigida por Diego Sánchez Meca.

Nietzsche, Friedrich, Obras Completas. Madrid, Tecnos, 2011-2016, 4 vols. Edición dirigida por Diego Sánchez Meca.

Ortega y Gasset, José, La rebelión de las masas, Madrid, Revista de Occidente, 1972.

Ortega y Gasset, José, "Relativismo y racionalismo", en Obras Completas III. Madrid: Alianza, 1983, pp. 157-162.

Ortega y Gasset, José, "Las dos ironías, o Sócrates y Don Juan”, en Obras Completas III, Madrid, Alianza, 1983, pp. 174-178.

Ortega y Gasset, José, "El tema de nuestro tiempo", en Obras Completas III, Madrid: Alianza, 1983, pp. 145-203.

Parra Pujante, Antonio, Periodismo y verdad. Filosofía de la verdad periodistica, Madrid, Biblioteca Nueva, 2003.

Peters, Michael A., "Education in a post-truth world", Educational Philosophy and Theory, 49(6), 2017, doi: 10.1080/00131857.2016.1264114 
Pérez Gutiérrez, Mario, El fenómeno de la información. Una aproximación conceptual al flujo informativo, Madrid, Trotta, 2000.

Romero Cuevas, José Manuel, "Perspectivismo y crítica social. De Nietzsche a la Teoría Crítica”, Logos. Anales del Seminario de Metafísica, 48, 2015, pp. 141-163. doi: 10.5209/rev_ASEM.2015.v48.49278

Sinova, Justino, "Periodismo", en A. Cortina y J. Conill (dir.), 10 palabras clave en ética de las profesiones, Estella, Verbo Divino, 2000, pp. 257-286.

Stellino, Paolo y Tinland, Olivier (dir.), Nietzsche et le relativisme, Bruxelles, Ousia, 2019.

Vattimo, Gianni, El sujeto y la máscara, Barcelona, Península, 1989.

Vattimo, Gianni, "Post-modernidad, tecnología, ontología”, en F. Jarauta, (ed.), Otra mirada sobre la época, Murcia, Colegio Oficial de Aparejadores y Arquitectos, 1994.

Wittgenstein, Ludwig, Tractatus lógico-philosophicus, Madrid, Tecnos, 2007.

Wotling, Patrick, "Génealogie (Genealogie)", en D. Astor (dir.), Dictionnaire Nietzsche, Paris, Laffont, 2017, pp. 368-373.

DOI: https://doi.org/10.15366/bp.2020.24.008

Bajo Palabra. II Época. No 24. Pgs: 157-176 
